\title{
German Professors' Motivation to Act as Peer Reviewers in Accreditation and Evaluation Procedures
}

\author{
Sandra Ohly ${ }^{1}\left[\right.$ Christian Schneijderberg $^{2}(\mathbb{0}$
}

Accepted: 10 December 2020 / Published online: 9 January 2021

(C) The Author(s) 2021

\begin{abstract}
Acting as a reviewer is considered a substantial part of the role-bundle of the academic profession (quality assurance (QA) and quality enhancement (QE) role). Research literature about peer review, for example, for journals and grants, shows that acting as a peer reviewer adds to an academic's reputation. However, little is known about academics' motivation to act as reviewers. Based on self-determination theory, the multidimensional work motivation scale (Gagné et al. 2015) is used for a survey of German professors acting as reviewers. The results of factor analysis show no intrinsic motivation to act as a reviewer in accreditation and evaluation procedures. Presumably, due to socialization effects, identified motivation among professors is higher compared to introjected motivation or to extrinsic motivation. A preference for HEI leadership/management predicts identified motivation to act as a reviewer, but a preference for teaching does not. Overall, the results suggest that professors acting as peer reviewers in accreditation and evaluation procedures accept the ambivalence of being self-determined in exercising the QA and QE professional role and of involuntarily being a management tool for higher education governance. The findings suggest that peer reviewing - also of research - is based on identified (and introjected) and not intrinsic motivation, for example, socialized acceptance of journal peer review as the best or most suitable mechanism of QA and QE.
\end{abstract}

Electronic supplementary material The online version of this article (https://doi.org/10.1007/ s11024-020-09430-5) contains supplementary material, which is available to authorized users.

Christian Schneijderberg

schneijderberg@incher.uni-kassel.de

1 Chair Business Psychology, University of Kassel, Kassel, Germany

2 International Centre for Higher Education Research, University of Kassel, Kassel, Germany 
Keywords Academic profession - Accreditation and evaluation procedures .

Germany · Peer review · Quality assurance and enhancement · Self-determination theory

\section{Introduction}

In Germany, quality assurance (QA) and quality enhancement (QE) of research and teaching are based on the tradition of a social partnership (Sozialpartnerschaft) between the academic profession and the state (Ringer 1990; Schimank 2005; Stichweh 1994). A fundamental pillar of the social partnership is the freedom of research and teaching granted to the academic profession by the state (Grundgesetz: article 5 (3) 1). The social partnership stresses the cooperative governance of higher education institutions (HEIs) with separated competencies: The state is responsible for law-making and the funding of research and teaching, and the academic profession for the execution (law-applying) and quality of research and teaching (e.g., Schimank 2005). An example and outcome of the social partnership is the stateestablished higher education accreditation regime (HEAR). Representatives of the German federal states and the German Rectors' Conference jointly decide on the organizing of QA procedures and relevant accreditation criteria (Akkreditierungsrat 2013; Hochschulrektorenkonferenz 2016; Kultusministerkonferenz 2017a, 2017b). QA and QE criteria address the organizing of studies and teaching and HEIs' quality management (Akkreditierungsrat 2001). In addition to participating in the "institutional estate" (Pusser 2008) of the accreditation council, the social partnership requires the academic profession to participate in accreditation and evaluation review groups. Academics accordingly become part of the higher education governance regime on a second level, which is why Musselin (2013a: 1170) defines reviewers as "management tools" for the establishment of a new normative definition of study programs and teaching according to the New Public Management "doctrine" (Power 1999: 93).

Based on the brief description above, this article will tackle the research question of what motivates academics to participate in review groups for accreditation and evaluation procedures. From a governance perspective, the social partnership established in HEAR builds on the participation of academics in relevant, governing positions inside HEIs (e.g., as presidents and deans) and outside of HEIs (e.g., representatives in the accreditation council). From a QA perspective, the HEAR social partnership includes academics in general and professors in particular who participate in the reviewing of QA systems and the organization of studies and teaching in HEIs and of more than 8,000 study programs in Germany (see: www.hochschulk ompass.de). Accordingly, it is the social partnership that has to be addressed when analyzing reviewers' motivation and not the accreditation agencies, which organize procedures closely controlled by the state (Serrano-Velarde 2014: 102).

The participation of academics in the systems, organizational and individual levels is fundamental for the self-governance of the academic profession (Clark 1983; Kogan and Teichler 2007; Macfarlane 2010; Ringer 1990; Scholkmann 2011). According to Merton (1976), the social partnership with the state creates norm 
conflicts for the academic profession, which struggles with the ambivalence of social (state) structures, group and individual influences. From a sociological stance, "ambivalence becomes a manifestation of contradictions, which stem from social actors' [relations and] transactional engagement with others" (Hillcoat-Nallétamby and Phillips 2011: 207). Compared to the application of primarily implicit criteria for QA and QE in research (e.g., Frey 2003; Hirschauer 2004; Roumbanis 2019), the QA and QE based on written criteria for accreditation and evaluation procedures (Bornmann et al. 2006; Schneijderberg and Steinhardt 2019) can be a source of ambivalence for academics (Langfeldt et al. 2010). In comparison to QA and QE as pertains to the organization of studies and teaching, QA and QE in research are less ambivalent. In the social partnership of the state and the academic profession, the state provides grant money for national research foundations for academics to distribute (e.g., Derrick and Samuel 2016; Lamont 2009; Langfeldt 2001, 2006; Olbrecht and Bornmann 2010). Autonomous from the state but (ambivalently) dependent on publishers is the academic profession concerning QA and QE of journal publications (e.g., Armstrong 1997; Cole 1998; Bornmann 2011; Hirschauer 2004). The German social partnership of the state and the academic profession is explained after providing an overview of peer review motivation literature.

To study academics' motivation (not) to peer review, we connect sociological (macro- or systems-level) with psychological (micro- or individual-level) notions of social ambivalence by applying self-determination theory (SDT; Deci and Ryan 1994). The psychological notion of extra-role and in-role decision frames by Northcraft and Tenbrunsel (2011) can only grasp what motivates academics to participate in peer review and not the what, how and why questions of peer review. The what, how and why questions of peer review are rooted in the macro-organizing structures of the academic profession and in the attitudes, academics identify with during their socialization. The empirical basis is survey data of 1,898 professors, which was collected in the research project "External and internal quality assurance of studying and teaching via processes of accreditation and evaluation" (in German: Externe und interne Qualitätssicherung von Studium und Lehre durch Akkreditierungs- und Evaluationsverfahren (EIQSL)).

\section{Academic Profession, Peer Review, and Reviewers' Motivation}

\section{Studying Academics’ Motivation (not) to Peer Review}

Both the self-governance and the reviewer roles are part of the tasks and identity of an academic professional in Germany and elsewhere (e.g., Henkel 2005; Kogan and Teichler 2007; Macfarlane 2010). Nevertheless, research literature suggests a tension between organizational demands and the individual autonomy of academics (e.g., Langfeldt 2006; Musselin 2013b). Interestingly, sociological as well as higher education and science studies literature always refers to the autonomous, intrinsic motivation of academics - mostly with reference to the Mertonian norms of science (Merton 1973; see also Curtin et al. 2018) - delineating the intrinsic from the extrinsic, i.e., incentivized behavior. Theoretically, the term intrinsic is a rather narrow 
approach to the motivation of academics, as their behavior is not natural but subject to socialization (e.g., Schneijderberg and Teichler 2018). Academic socialization is about the identification with and commitment to an academic's role, which has been both normatively and individually defined in specific cognitive and social environments (Trowler 2014; Bronfenbrenner 1979; Sanford 1966).

However, research on what motivates academics to participate in peer review shows that academics' socialized attitudes need to be transformed into motivated action. For example, Northcraft and Tenbrunsel (2011) conceptualize the locus of responsibility according to the binary frames of peer review being motivated by academics' in-role (part of the job) and/or extra-role choice (enjoyment and status provision). Applying the concept by Northcraft and Tenbrunsel (2011), Zaharie and Osoian (2016) identified in a semi-structured interview study with Romanian academics that peer review motivation depends on three frames (journal quality/reputation, identification with the scientific community, and match of reviewer's expertise and manuscript) and on balancing the incentives of benefits over the costs. In addition to expectable cognitive (e.g., to guard quality standards) and social (e.g., relationship with the editor) motivations, the interviewees report being motivated by financial rewards (membership fees and publication discounts) and expected career boost (e.g., professional development, rewards from the journal and privilege when submitting). The costs include among others having to deal with low-quality papers, taking responsibility for errors, and editors and authors disregarding the review suggestions. Zaharie and Osoian (2016: 75) conclude: "While most participants in the sample do not consider it a task imposed by their job description, they see it as a requirement of being a researcher, an in-researcher role responsibility." A similar answer to the question of what motivates reviewers is provided by Schroter et al. (2010). They show that peer reviewers evaluating biomedical research grants rely on a sense of professional duty, and they aim for fair review in the face of the costs of not receiving recognition for the time-consuming service to the community (see also Curtin et al. 2018; Gallo et al. 2020; Nobarany et al. 2015). Because of the ambivalence inherent in the accreditation procedure, it is unclear if and how these results transfer to reviewing in accreditation.

\section{Self-Determination Theory (SDT) to Study Academics' Motivation}

The brief literature overview presents the motivation (not) to peer review as a multi-faceted and multi-layered socio-psychological appreciation of academics' values. To take a more differentiated look at academics' motivation to be involved in accreditation and evaluation review panels, the research question "What motivates academics to participate in review groups for accreditation and evaluation procedures?" is addressed using psychological SDT (Deci and Ryan 1994). SDT suggests a multidimensional conceptualization of motivation ranging on a continuum from autonomous regulation of behavior (intrinsic motivation) to complete external regulation. Accordingly, SDT provides a more fine-grained motivation scale to address the academics' locus of responsibility (Northcraft and Tenbrunsel 2011). Intrinsic motivation, the motivation to do an activity for its own sake because it is fun or 
pleasurable, is the most autonomous form of behavior regulation. Intrinsic motivation in part captures what Northcraft and Tenbrunsel (2011: 1280) framed as an "extra-role choice." The frame of in-role motivation (reviewing as part of the job) in SDT terms is differentiated according to identified, introjected and extrinsic motivation. Identified regulation refers to the motivation to do an activity because it is in line with personal values and beliefs, i.e., based on academics' socialization. For example, an individual will exert effort on behavior when he or she believes it is important. In introjected regulation, the reasons for action are only partially internalized, i.e., they involve only partial ego-involvement or self-evaluation. An individual will exert effort on a behavior to avoid negative feelings such as guilt or shame. Extrinsic motivation, the least autonomous form of motivation, is the motivation to act in order to obtain social or material rewards or to avoid punishment (such as disapproval) from significant others. This form is similar to Northcraft and Tenbrunsel's (2011) extra-role choice for social reasons. SDT postulates that humans have innate psychological needs for autonomy, competence and relatedness, and that the satisfaction of these needs provides the nutrients for intrinsic motivation and internalization. The different forms of motivation are assessed with the multidimensional work motivation scale (MWMS; Gagné et al. 2015), which was adapted to fit the needs of our survey, which covered 2,704 reviewers involved in the accreditation and evaluation of study programs and HEI QA systems.

Autonomous forms of motivation have been linked to desirable outcomes, such as higher levels of job satisfaction, work performance and better health and wellbeing (for a review, see Howard, Gagné and Bureau 2017). Specific work behavior has been examined less often, although research has also pointed out that discretionary (work) behavior such as knowledge sharing (Foss et al. 2009) or voting in political elections (Koestner et al. 1996) benefits from autonomous forms of motivation. In the academic field, autonomous forms of motivation have been linked to the teaching motivation of junior academics (Esdar et al. 2016). In comparison to Northcraft and Tenbrunsel (2011) not differentiating intrinsic and extrinsic motivation, we therefore connect our theorizing about the motivation to act as a reviewer and SDT. To do so, we modify the research question to "Which of the four forms of motivation (intrinsic, identified, introjected, and extrinsic) motivate academics to participate in review groups for accreditation and evaluation procedures?" To answer our research question, the theoretical approach of SDT is combined with that of the sociology of professions, which is presented in the following section.

\section{Peer Review and Reviewers' Motivation to Participate in Accreditation Procedures}

The commitment to peer review as a basis for judging science is deeply rooted in academic culture, and has been largely accepted in the [...] public funding of science.

The academic practice of peer review which underpins decisions on the funding, and sometimes the publication, of scientific research [...] is a form of selfregulation. (Solesbury 1996: 19) 
The question of what motivates academics to participate in peer review is entangled with the what, how and why questions of peer review. The two quotes from Solesbury (1996) summarize the two basic social and cognitive principles of peer review - acceptance by the academic profession as a form of self-regulation and the adoption by the state for funding distribution and allocation. ${ }^{1}$ In comparison to the general why, the how and what questions are more complex to answer. Generally, peer review is defined as being conducted by heterogeneous, (more-)internationallyoriented academic elites who build their normative judgment on implicit academic criteria, especially for research and teaching evaluation, but also includes explicit extra-academic criteria, especially for governance evaluation (Musselin 2013a). The opportunities to influence the (academic) norms of how to conduct research, teaching, and governance vary by subject of peer review. QA and QE for both journal and grant peer review are in the expert hands of academics. Peer review is based on implicit academic criteria such as originality and newness of research (e.g., Lamont 2009; Langfeldt 2001, 2006).

The what, how and why questions of peer review and, as a consequence, the question of what motivates academics to participate in accreditation and evaluation peer review, have to be regarded in the specific German context. In comparison to other countries (Arribas-Ayllon and Bartlett 2014), German professors have rather high obligatory teaching loads: eight or nine term hours (Semesterwochenstunden) for university professors and 16 to 18 term hours per term (one academic year has two terms) for professors at Universities of Applied Sciences. In 2015, about $95 \%$ of academics were employed in public HEIs (GFSO 2016), i.e., employed by the state. Historically, the state-academic profession relationship is a delicate issue. For example, Ringer (1990: 36) wrote that associate and full professors, as salaried government officials, were "subject to prosecution for bearing unworthy of their position in private as well as in public life," according to the Prussian General Code and Disciplinary Law of 1852. The historical example shows that accreditation and evaluation peer review in the social partnership of the state and academic profession is more than "a particularly unique volunteer dilemma" (Northcraft and Tenbrunsel 2011: 1278). From a governmental perspective, tenured full professors in particular can be expected to participate in accreditation and evaluation peer review on their statesalaried working time.

This answer as to why academics should/could be motivated to participate in peer review can be complemented by answering the how question of accreditation and evaluation peer review. In comparison to journal and grant peer review, the accreditation and evaluation criteria that academic peer reviewers have to respect

\footnotetext{
1 The peer review goals of QA and QE are augmented by what Solesbury (1996) defines as the threestage decision algorithm comprising 'fitness for purpose' (engineering concept), 'knowledge added' (economic concept of value added), and 'value for money' (business concept) for funder-initiated QA and QE. Solesbury (1996) is explicit about the three-stage decision algorithm both demystifying and defending peer-review practice. Notwithstanding the insufficient transparency of criteria for research evaluation, the three-stage decision algorithm works as a proxy for public accountability to a) identify unfit and scientifically invalid research, b) justify the knowledge gain from funded research, and c) facilitate making choices within limited budgets.
} 
are written down, i.e., made (more) explicit (Akkreditierungsrat 2013; Kultusministerkonferenz 2017b; see also ENQA 2015). Analyzing the German accreditation criteria, Schneijderberg and Steinhardt (2019) show that they are a mix of more implicit quality and more explicit governance goals. The ambivalence of governance QA and professional QE is also a common feature of the evaluation of teaching in Germany (Mittag 2006). For example, Bornmann et al. (2006) found in a survey that $93 \%$ of the reviewers agreed that criteria-led evaluation procedures achieve the goals of QA and of QE. ${ }^{2}$ However, such findings cannot be taken for granted. For example, Langfeldt et al. (2010) summarize the findings of an empirical study in Norway that written accreditation and evaluation criteria and indicators are intended to assure equity among those accredited or evaluated, to guide reviewer decisionmaking, and provide limits to professional peer discretion. These findings suggest that written criteria for accreditation and evaluation influences the reviewers' behavior, and, therefore, the behavior of reviewers is not fully self-determined.

Similar to Norway, German HEAR was criticized as an attempt by the state to influence the governance of teaching and, accordingly, for threatening academic freedom (Baumann and Krücken 2019). The ruling of the constitutional court (Bundesverfassungsgericht 2016) reminded the actors in the social partnership of the state and the academic profession of their separate and joint duties. The state has to assure the quality provision of teaching and learning or studies in general. The academic profession is in charge of assuring the quality provision of teaching and learning or studies in particular (an answer to the what question). In legal terms of the modified accreditation regulation (Kultusministerkonferenz 2017a, 2017b), the academic profession provides reviewers for QA and QE, in the accreditation council both representatives of the academic profession and the state take the final accreditation decision, and the state provides funding for accredited study programs and HEIs. Building on Clark (1983), Pusser (2008) refers to these representatives of the academic profession as the "institutional estate" of the academic oligarchy.

Summing up the literature on the academic profession and academics' motivation (not) to peer review, it becomes evident that peer review remains a legitimate - and legitimizing - central mechanism for awarding reputation, distributing funding, pursuing (normative) goals, changing governance regimes, etc. The literature presents peer review and the underlying ideal of QA and QE as a fundamental part of the self-governance of the academic profession (Bornmann 2011; Kogan and Teichler 2007; Mulkay 1976; Solesbury 1996) and of the social partnership with the state (Ringer 1990; Schimank 2005). Consequently, we expect that, compared to other forms of motivation, identified motivation is strongest among reviewers (highest mean level) in our hypothesis 1 (H1).

Consistent with the findings from motivation literature (e.g., Nobarany et al. 2015; Schroter et al. 2010), it is assumed that reviewers' agreement with the aims of QA and $\mathrm{QE}$ is positively related to their motivation to act as a reviewer $(\mathrm{H} 2 \mathrm{a})$. Because participation in accreditation and evaluation procedures is part of academic self-governance

\footnotetext{
${ }^{2}$ Irrespective of whatever vague review criteria exist, this finding would suggest that the locus of control of evaluation lies with the self-determined and autonomous reviewer.
} 
- for example, similar to each German professor being expected to serve her/his term in office as dean or vice-dean (Scholkmann 2011) - we assume that academics who prefer teaching $(\mathrm{H} 2 \mathrm{~b})$ and who prefer leadership and management $(\mathrm{H} 2 \mathrm{c})$ positively relate to identified motivation to act as a reviewer. Since evaluations are perceived to be an elite (Musselin 2013a) and (oligarchic) gatekeeping (Curtin et al. 2018; Pusser 2008; Ware 2011) activity among the members of the academic profession, we assume that we will find more professors in the highest rank (W3/C4) acting as reviewers (H2d) than would be expected based on the share of W3/C4 professors at German HEIs. In 2015, the W3/C4 share was about 32\% among full professors (GFSO 2016). Based on SDT, we expect that the perceived usefulness (e.g., for students and HEIs) of the accreditation and evaluation procedures by professors is positively related to identified motivation to act as a reviewer (H2e). Theoretically, higher values of the attitude of perceived usefulness of accreditation and evaluation procedures would indicate lower ambivalence of academics, for example, toward more explicit criteria. Furthermore, identified motivation is related to lower levels of doubt about re-engaging as a reviewer in the future (H3a), satisfying the basic needs of autonomy, application of competencies and social relatedness. In contrast, other forms of motivation (introjected and extrinsic) will be positively related to doubts ( $\mathrm{H} 3 \mathrm{~b}$ ). $\mathrm{H} 3$ a roughly captures the incentives side and $\mathrm{H} 3 \mathrm{~b}$ the costs side of peer reviewing (Zaharie and Osoian 2016). The results testing these hypotheses will be presented after the description of the empirical study in the next section.

\section{The Study}

The survey was conducted both online and in written form in 2015. We received 2,704 completed questionnaires from the sample of 5,936 reviewers (response rate 45.6\%) - the responses cover about $30 \%$ of all active reviewers, based on the list of the Hochschulkompass, which is provided by the German Accreditation Council. On average, respondents took 37 minutes to complete the questionnaire. Among the 2,704 observations were 1,942 responses from academics (the remaining were practitioners or students), of which 1,898 were professors. Professors were on average 57.00 years old (SD $=13.83)$ and had worked in academia for an average of 23.56 years $(\mathrm{SD}=10.73)$. Further characteristics are presented in Table 1. The strong representation of professors in the sample is easy to explain due to a) being the majority in review groups (three or more representatives) and b) their permanent employment and public visibility. In contrast to professors, students and non-professorial staff in particular leave HEIs after a certain amount of time and are thus very difficult to contact for the purposes of a survey.

\section{Limitations}

In general, it is difficult to be certain about the representativeness of our study. According to the German Federal Statistical Office (GFSO 2016), in 2015, 46,344 professors were employed at German HEIs, of which 10,535 were females (22.7\%), 
Table 1 Respondents according to rank, gender, employment status and disciplines. Source: EIQSL study

\begin{tabular}{ll}
\hline & $\mathrm{N}$ (percent) \\
\hline Professors & 1,898 \\
Ranks & $706(37.2 \%)$ \\
Highest rank (C4/W3; equivalent to full professor) & $868(45.7 \%$ \\
Second-highest rank (C3/W2; equivalent to associate professor) & $122(6.4 \%)$ \\
Third-highest rank (C2/W1; equivalent to (non-)tenured assistant professor) & \\
Gender & $394(20.8 \%)$ \\
female & $1,477(77.8 \%)$ \\
male & \\
Employment status & $1,539(81.1 \%)$ \\
Active & $324(17.1 \%)$ \\
Retired & \\
Discipline groups & $108(5.7 \%)$ \\
Engineering (incl. architecture) & $304(16.0 \%)$ \\
Humanities (incl. languages, culture, and psychology) & $329(17.3 \%)$ \\
Mathematics and natural sciences & $214(11.3 \%)$ \\
Social sciences (incl. economics and law) & $943(49.7 \%)$ \\
Other (e.g., agriculture and sport) and no answer & \\
\hline
\end{tabular}

and 1,707 were active, guest and retired professors. The 1,539 active professors in the sample account for $3.3 \%$ of the total population. Admittedly, we know little about the self-selectivity, and we have to assume that professors opposing HEAR and professors with a strong preference for research might not be represented in the sample. However, empirical studies show that a majority of reviewers responds to review requests, without gender differences, and that participation in peer review is uneven (Gallo et al. 2020; Fox et al. 2017). These findings suggest an acceptable coverage of the total population of professors in German HEIs. Similar to journal and grant peer review, professors are usually recruited by accreditation agency representatives, in most cases depending on their disciplinary affiliation and/or selfgovernance experience, and sometimes on the basis of a recommendation by a colleague already acting as a reviewer in accreditation and evaluation procedures. In addition, professors can contact accreditation agencies and become peer reviewers, ideally after passing agency training (Akkreditierungsrat 2001, 2013).

\section{Questionnaire}

Responses to all items were given on a five-point Likert scale ranging from $1=$ totally true to $5=$ not at all true. Responses were recoded so that higher values indicate stronger agreement. 


\section{Adaptation of the Multidimensional Work Motivation Scale (MWMS)}

The survey employed selected, but not all, items from the MWMS developed by Gagné et al. (2015) (Table ESM1 in Electronic Supplementary Material; the questionnaire was in German and relevant items are translated into English by the authors). During pretesting, we found that the MWMS caused substantial context effects (Mummendey and Grau 2014; Schwarz and Sudman 1992). Since the MWMS was not the core of the survey, we took a pragmatic approach towards modifying the MWMS in order to focus on reviewers' experiences with accreditation and evaluation procedures, and drew on other surveys about teaching motivation for inspiration (Esdar et al. 2016; Visser-Wijnveen et al. 2012). After two rounds of pretesting (both with and without telephone contact to a project researcher), the first modification arose from professors' refusal to respond to certain items. For example, typical responses to Introj 1 were that among all accreditation and evaluation reviewers, professors were the most capable for the job; and professors protested about and/or became severely annoyed about the sameness of items (e.g., Intrin2 and Intrin3; Ext-Mat2 and Introj1; Table ESM1), which professors interpreted as redundancy and poor questionnaire design. The item "because I risk losing my job if I don't put enough effort in it" (Ext-Mat3) was not used because full professors are civil servants for life and can only be fired under exceptional circumstances in Germany.

During the first round of pretesting, professors protested rather strongly against what they perceived as a psychological test. Accordingly, the MWMS items were modified to fit the context and were included in section 3 of the questionnaire addressing the reviewer's qualifications and motivation to participate in accreditation and evaluation procedures. The questionnaire was organized according to the following sections. Section 1: General information about respondents; Section 2: Experience as an accreditation and evaluation reviewer; Section 4: Questions concerning the last accreditation or evaluation procedure the reviewer participated in; Section 5: General opinions about QA and HEAR; and section 6: Motivation to continue or stop working as a reviewer. With the aim of maximizing the response rate, the amotivation items from the MWMS were put into section 6 to shorten the motivation questions in section 3 . In section 6 , the amotivation items were formulated either in a negative manner for those professors who had seriously considered no longer working as a reviewer in accreditation and evaluation procedures or else in a positive manner for those professors who had not.

The context-related modification of items and the separation of amotivation from the four other motivation forms also meant that we did not use the MWMS stem "Why do you or would you put effort into your current job?" The stem for the four types of motivation is: "To what extent do the following statements describe your personal motivation to participate as a reviewer in QA procedures? I work as a reviewer because..." As indicated above, the amotivation items were separated into two different questions: "To what extent do the following statements apply to your serious consideration of no longer acting as a reviewer in QA procedures? I have seriously considered no longer working as a reviewer because..."; and: "If you answered "no" to question [...], why have you never seriously considered stopping 
to work as a reviewer in QA procedures? I never seriously considered stopping to work as a reviewer because..." As the amotivation items only lead to the futureoriented question, they were not used for the statistical analysis of professors' peer review motivation. A fourth modification of Gagné et al.'s (2015) MWMS is the use of a five-point Likert scale ( 1 = "completely," 5 = "not at all") instead of the sevenpoint Likert scale (1 = "not at all," 2 = "very little," 3 = "a little," 4 = "moderately," $5=$ "strongly," $6=$ "very strongly," 7 = "completely") based on pretesting.

Because we made considerable adaptations to the MWMS, exploratory factor analysis with varimax rotation was employed to explore the factor structure of the revised instrument. The analysis resulted in six factors with Eigenvalues $>1$. Based on the inspection of the screen plot, three factors were identified which explained $45.50 \%$ of the variance. The three factors were labeled based on the highest loading item from the MWMS. The first factor ("identified") motivation has loadings $>.40$ from three items targeting identified motivation, two items targeting intrinsic motivation and two items that were added to the questionnaire after pretest ("to contribute to strengthening the autonomy of academia and teaching"; "because it is important to me to do something for society"). The second factor, labeled "extrinsic (social)" had loadings $>.40$ from one item of the extrinsic social subscale, one item of the identified subscale and two items that were added after the pretest ("because it is important to me to do something for society"; "because I was asked to do it"). The third factor, labeled "introjected," showed loadings from one item of the extrinsic (social) subscale, one item of the introjected subscale, and one item of the intrinsic motivation subscale. To reduce overlap between the factors, cross-loading items were not considered further.

This procedure led to an identified motivation subscale consisting of four items (Cronbach's alpha $=.67$ ), an extrinsic (social) subscale of two items (Cronbach's alpha $=.60)$ and an introjected subscale of two items (Cronbach's alpha $=.74)$. The three scales show the expected pattern of intercorrelations based on SDT. Specifically, two adjacent forms of motivation in the continuum showed low intercorrelations (internal with introjected $r=.22, \mathrm{p}<.001$; introjected with extrinsic $r=.25$, $\mathrm{p}<.001)$, and identified motivation was unrelated to extrinsic motivation $(\mathrm{r}=.01, \mathrm{p}$ $=64$ ), which is in line with theoretical assumptions and empirical findings (Howard et al. 2017). Further support for the distinctiveness of the scales is provided by their unique pattern of correlations with demographic variables (age, length of academic tenure, current position).

\section{Role and Effects of Accreditation and Evaluation Procedures}

To assess the reviewers' view of the accreditation and evaluation procedures (Table ESM2, electronic supplementary material), we asked about the perceived effects of external QA procedures using 16 items and the following question: "To what extent do you agree with the statements concerning the impact of external quality assurance? External QA procedures...”). Factor analysis using varimax rotation revealed two factors with Eigenvalues $>1$, which we labeled "perceived usefulness for students" and "perceived usefulness for HEI." Sample items are: "...contribute to the 
opportunity to complete a course of studies in regular time" for the first factor and "...support the government of studying and teaching within HEIs" for the second factor.

To assess the perceived role of accreditation for $Q A$ in Germany, participants rated their agreement with 11 items (scale $1=$ "completely", $5=$ "not at all"). The following item stem was used: "To what extent do you agree with the statements concerning the functions of external quality assurance? External QA procedures..."). Two factors with Eigenvalues $>1$ emerged from exploratory factor analysis. We labeled the first factor, which consisted of two items, "governance" ("serves to govern universities") and the second factor, consisting of 10 items, as "quality assurance" (e.g., "contributes to the development of quality in study and teaching").

To assess academics' preferences, participants rated their agreement with two items. The following items were used: "Judging your own preferences, do they lie primarily in teaching or in research?" $(1=$ primarily in teaching to $5=$ primarily in research) and "Judging your own preferences, do they lie primarily in the area of research and teaching or in the area of leadership and management?" $(1=$ primarily in teaching and research to $5=$ primarily in leadership/management).

To test H1, we compared the mean level of identified motivation to that of introjected or extrinsic motivation using the t-test for dependent samples. To test our hypotheses $\mathrm{H} 1$ and $\mathrm{H} 2 \mathrm{a}-\mathrm{e}$, we regressed identified, introjected, and extrinsic motivation on perceived usefulness of the accreditation system, role of the accreditation system, and individual characteristics of the respondents (rank). In the analyses, we controlled for age, gender, type of HEI (University of Applied Sciences, university or other), area of expertise, status (retired or active) and number of previous engagements as a reviewer in accreditation and evaluation procedures. We also controlled for tenure in academia, tenure as department leader and tenure in leadership of HEI. To test H3, we regressed doubts as a binary variable on our predictor variables using a logistic regression analysis.

\section{Results}

H1 states that the primary motivation of reviewers is identified motivation. Our results confirm this hypothesis. Identified motivation is higher compared to introjected motivation $(\mathrm{t}=89.95, \mathrm{df}=1741, \mathrm{p}<.000$; see Table ESM2 for means and standard deviations) and extrinsic motivation $(\mathrm{t}=18.56, \mathrm{df}=1766, \mathrm{p}<.000)$.

Concerning $\mathrm{H} 2 \mathrm{a}$, assuming that participants will endorse the role and effects of accreditation, we found ratings around the midpoint of the scale for the goal of QA, indicating moderate agreement (see Table ESM1 for means and standard deviations). Of note is that agreement with the goal of QA predicts participants' identified motivation to act as reviewer, which also supports $\mathrm{H} 2 \mathrm{a}$.

$\mathrm{H} 2 \mathrm{~b}$ and $2 \mathrm{c}$ stipulate that the preferences for teaching and for management/leadership over teaching/research are positively related to motivation to engage as a reviewer. As shown in Table 2, the preference for teaching does not predict identified motivation. Thus, $\mathrm{H} 2 \mathrm{~b}$ is not supported. H2c receives support because the preference for management/leadership is positively related to identified motivation to 
Table 2 Predicting identified motivation. Source: EIQSL study

\begin{tabular}{lrrrrr}
\hline & \multicolumn{1}{l}{ B } & SE & \multicolumn{1}{c}{ Beta } & \multicolumn{1}{l}{ T } & \multicolumn{1}{l}{$\mathrm{p}$} \\
\hline Intercept & 1.18 & 0.25 & & 4.78 & 0.00 \\
Frequency of prior accreditation commitment & 0.00 & 0.02 & 0.00 & 0.07 & 0.95 \\
Age & 0.00 & 0.00 & 0.04 & 1.15 & 0.25 \\
Gender & -0.08 & 0.05 & -0.04 & -1.70 & 0.09 \\
Humanities/Social/Business & -0.05 & 0.06 & -0.04 & -0.97 & 0.33 \\
Science/Engineering & 0.05 & 0.06 & 0.03 & 0.78 & 0.44 \\
U Applied Sciences & -0.07 & 0.09 & -0.04 & -0.80 & 0.43 \\
University & -0.13 & 0.09 & -0.08 & -1.48 & 0.14 \\
Tenure in academia & 0.00 & 0.00 & 0.00 & 0.12 & 0.90 \\
Y of experience in leadership position in department & 0.01 & 0.00 & 0.04 & 1.45 & 0.15 \\
Y of experience in leadership position in university & -0.01 & 0.01 & -0.03 & -1.06 & 0.29 \\
Status (1 = active, 0 = retired) & 0.09 & 0.07 & 0.04 & 1.29 & 0.20 \\
Current rank & 0.03 & 0.02 & 0.04 & 1.35 & 0.18 \\
Preference teaching & -0.03 & 0.02 & -0.04 & -1.48 & 0.14 \\
Preference management & 0.06 & 0.02 & 0.08 & 3.07 & 0.00 \\
Perceived usefulness for students & 0.22 & 0.04 & 0.24 & 5.86 & 0.00 \\
Perceived usefulness for HEI & 0.00 & 0.02 & 0.00 & -0.15 & 0.88 \\
Government & 0.09 & 0.02 & 0.12 & 4.72 & 0.00 \\
Quality assurance & 0.23 & 0.04 & 0.25 & 6.10 & 0.00 \\
\hline Applied science (1 = ys, & & & &
\end{tabular}

Applied science $(1=$ yes, $0=$ no). Current position $(\mathrm{W} 3=1, \mathrm{~W} 2=2, \mathrm{~W} 1=3)$

engage as a reviewer. As can be seen in Tables ESM3 and ESM4 (electronic supplementary material), the preferences do not predict introjected or extrinsic motivation.

In $\mathrm{H} 2 \mathrm{~d}$, we assumed that the majority of reviewers would be of highest rank (W3/ $\mathrm{C} 4)$. Contrary to this assumption, we found that $37.2 \%$ were professors in the highest rank (C4/W3), 45.7\% were in the second-highest rank (C3/W2) and 6.4\% were in the third rank (C2/W1). Compared to the total population of professors, in this sample $\mathrm{W} 3 / \mathrm{C} 4$ are only slightly overrepresented in review groups $(33 \%$ of $\mathrm{W} 3 / \mathrm{C} 4$ compared to $50 \%$ of C3/W2 and 17\% of C2/W1; GFSO 2016: 41). Contradicting the hypothesis, the rank of professorship does not predict motivation to act as a reviewer (Tables 2, ESM3 and ESM4).

Concerning $\mathrm{H} 2 \mathrm{e}$, we find that the perceived positive usefulness of the procedure for students significantly predicts identified motivation (Table 2). This result supports H2e. In contrast to H2e, perceived usefulness for HEIs did not predict identified motivation. The perceptions of usefulness do not predict introjected or extrinsic motivation (Tables ESM3 and ESM4).

Concerning $\mathrm{H} 3 \mathrm{a}$, we find support for the idea that individuals with high levels of identified motivation are more unlikely to express doubt about their future role as a reviewer (Table ESM5). In contrast to $\mathrm{H} 3 \mathrm{~b}$, introjected and extrinsic motivations are unrelated to the likelihood of having doubts. Accordingly, H3b is not supported. 


\section{Discussion of Results}

With regard to our research question, our results indicate that not all four forms of motivation proposed by SDT can be identified in the context of acting as a reviewer in accreditation and evaluation procedures. Specifically, items targeting intrinsic motivation ("because it is fun") did not clearly load onto a common factor but onto separate factors, which we identified as either identified or introjected regulation. This finding is not in line with previous research on reviewing in journals that did identify enjoyment, which would count as intrinsic motivation (Northcraft and Tenbrunsel 2011). These differences in findings might be due to the specifics of reviewing in accreditation and evaluation procedures.

Consistent with our expectation (H1), identified motivation was an important driver for acting as a reviewer. First, the mean of identified motivation (Table 2) was higher than the means of introjected (Table ESM3) and extrinsic motivation (Table ESM4). Second, identified motivation also consistently linked to the proposed predictors (attitudes towards the accreditation system; preference for teaching over research or management; Table ESM2) and outcome (doubts about acting as a reviewer again; Table ESM5).

Based on the theory of profession (e.g., Hackett 1990; Kogan and Teichler 2007; Schimank 2005), professors' (H2d) identified motivation to act as a reviewer in accreditation and evaluation procedures is interpreted as being the execution of professional academic norms in the specific cognitive and social environment created by the social partnership between the academic profession and the state in Germany. For example, professors participate in the institutional estate of the social partnership with the state, for example, in the accreditation council, which is responsible for defining the accreditation criteria. Historically, the social partnership is a source of recurrent tension between the state and the academic profession and varies over time (Ringer 1990; Schimank 2005). The social partnership for the specific governance of studying and teaching exists since the introduction of framework regulations for study programs in the 1970s (Schneijderberg and Steinhardt 2019). Based on the professional ambivalence of transactional engagement with the state, it does not seem right to consider professors simply as "management tools" (Musselin 2013a: 1170) in the governance of teaching and studying. Of course, the social partnership between the academic profession and the state creates a certain professional ambivalence "built into the very structure of social relations" (Merton 1976: 4). However, professors show an identified motivation to act as reviewers in accreditation and evaluation procedures, in spite of their generally lacking taste for HEI governance (factor: Perceived usefulness of QA for HEIs). The ontological dimension of ambivalence can also be observed among professors acting as reviewers in accreditation and evaluation. These professors are (possibly) establishing a (new) normative definition about the organization of studying and teaching. However, these professors act in the professional spirit and the "valuation" (Lamont 2012) of being a Hochschullehrer. The latter is supported by the finding regarding professors' self-determined engagement as reviewers, which cannot be taken for granted considering, 
for example, the findings from Norway about academics' reviewer role (Langfeldt et al. 2010).

The empirical observations of this study suggest that professors' identified motivation to act as a reviewer in accreditation and evaluation procedures is the result of a socialization process. For our sample of professors, we find identification with and commitment to the Hochschullehrer (higher education teacher) role, which is a fundamental part of being an academic professional (Stichweh 1994). Compared to the salient meaning of research for reputational gain among academics, high-quality teaching is of little importance for the reputation and remuneration of an academic (e.g., Klenke 2012; Schmid and Lauer 2016: 110-112). Among the professors in the sample, $38.9 \%$ prefer teaching, 34.8\% value teaching and research equally, and $23.3 \%$ prefer research. Controlling for differences among university and University for Applied Sciences professors, the tendency towards teaching preferences among the professors in the sample is slightly stronger than in empirical results from other studies (Müller and Schneijderberg 2020: 53).

The interpretation of professional ambivalence is also supported by professors' taste for teaching. Although the preference for management does predict identified motivation $(\mathrm{H} 2 \mathrm{c})$ and the preference for teaching does not $(\mathrm{H} 2 \mathrm{~b})$, professors generally have a preference for teaching/research (68.6\%) over management/leadership (10.5\%). $18 \%$ of the respondents value teaching/research and management/ leadership equally. As a reminder, identified motivation regulation (referring to the motivation to do an activity because it is in line with personal values and beliefs) is based on academics' socialization. Connecting the non-significant taste for teaching and significant management finding, the attitude of perceived usefulness of accreditation and evaluation procedures could be interpreted to lower ambivalence of academics, for example, toward more explicit review criteria. Accordingly, the lower ambivalence, i.e., lower or even non-contradiction of professors' "transactional engagement" (Hillcoat-Nallétamby and Phillips 2011: 207) on cooperation with the state seems to explain the link to academics' identified motivation. However, the interpretation of professional ambivalence amalgamation seems to be true only for a certain percentage of professors, which could be the subject for future research. The empirical results suggest an identified drifting apart or job-sharing of academics primarily engaged in either teaching or management/leadership. Professors' suspected teaching and management/leadership divide is supported by recent findings on the loosening of the research and teaching nexus because of the progressing vertical differentiation in the German HEI system (Müller and Schneijderberg 2020).

\section{Conclusions and Research Outlook}

The lack of empirical findings about the highly regarded intrinsic motivation of academics (Curtin et al. 2018; Merton 1973) acting as reviewers in accreditation and evaluation procedures indicates several directions for further research. Intrinsic motivation regulation expresses that the reasons for action are fully internalized and that the actions are based on full ego-involvement and self-evaluation (Deci and Ryan 1994; Gagné et al. 2015). For example, in the case of intrinsic motivation, 
the idealized search for truth based on full ego-involvement and self-evaluation of reviewers would make interdisciplinary agreement (Lamont 2009) rather impossible, due to reviewers being explicit about disciplinary QA and QE norms. Compared to intrinsic motivation, identified regulation refers to the motivation to do an activity because it is in line with personal values and beliefs, for example, based on socialization into the academic's role resulting in a normative identification with and commitment to specific cognitive and social environments (Henkel 2005; Macfarlane 2010; Schneijderberg and Teichler 2018; Trowler 2014).

The findings suggest that peer reviewing of research is also rather based on identified (and introjected) motivation and not on intrinsic motivation is supported by research findings about the acceptance of journal peer review as the best or most suitable mechanism of QA and QE, and professional governance (e.g., Cole 1998; Solesbury 1996). Identified motivation seems to wear off over the life course of seasoned academics, which provides a further glimpse into ambivalences of the academic profession. For example, the former editors of Research Policy address reviewer fatigue as "difficulties in finding referees willing to accept the task - this is unfortunately a growing problem; many researchers are claiming they are "too busy" or that it is "not their subject"; and regrettably some leading academics apparently believe that it is no longer their responsibility to make such 'public good' contributions" (Martin et al. 2009: 696). Identified motivation is also at the basis of results from studies about academics' motivation to peer review, for example, service to the academic community and QA and QE role (e.g., Curtin et al. 2018; Schroter et al. 2010). Research about reviewer's motivation also shows what is at stake when identified motivation to act as a peer reviewer is paralleled by introjected and extrinsic motivation. For example, the results by Gallo et al. (2020) and Zaharie and Osoian (2016) show that reviewers expect - and possibly are in reputational and material need of - social and monetary reward for reviewing. According to SDT, seeking social and/or material rewards (extrinsic motivation) is the least autonomous form of motivation because the motivation to act is based on an external locus of responsibility (see also Northcraft and Tenbrunsel 2011). The external locus of responsibility points to the thin line between ethical and unethical behavior as experienced by the academic professional. Extrinsic social motivation (to get colleagues' approval, greater respect and to avoid being criticized by others) provides clues for explaining research mainstreaming and blocking of innovation (e.g., Frey 2003) and the creation of an "invisible college" (Derrek and Beaver 1966), which can create material reward in the form of promotion to professor and/or higher income (e.g., Leahey 2007).

These results indicate that identified motivation - identified regulation refers to the motivation to do an activity because it is in line with personal values and beliefs - is important to consider in future research on reviewing in general, and on reviewing in accreditation and evaluation procedures specifically. Theoretically, approaching reviewer's motivation from the perspective of the sociology of profession allowed for the substantiation of peer review as a professional practice. Methodologically, the understanding of the socio-psychological ambivalence of peer review in accreditation and evaluation procedures did emphasize the context of relations, in this case between the German federal states and the academic 
profession. In addition, the theory-led approach connected well to the psychological SDT. Of course, the use of SDT and theory of professions could be viewed as double theorizing of a social phenomenon. To the contrary, however, we would argue that the connection of the sociological and psychological theories integrated the individual micro and systemic macro processes into a coherent research design, thereby connecting the what, how and why questions of peer review. First, our research design answers the what question beyond the binary framing of peer review as an extra-role and in-role (professional) decision dilemma (Northcraft and Tenbrunsel 2011; Zaharie and Osoian 2016). Second, the question of what motivates academics to participate in peer review is connected to the why question of peer review in the relationship of the academic profession and the state. Third, the what and why questions are approached in their entanglement with how peer review is done organized as a procedure and based on explicit, written criteria for QA and QE expert judgment.

The empirically supported considerations about the peer review of research are not meant to be provocative but to show the potential of a more differentiated approach to studying academics' motivation. For the study presented in this article, not all items from the MWMS (Gagné et al. 2015) were used and the selected items were modified to fit the context of the survey (Table ESM1). The pragmatic modification of the MWMS raises the question of validity (see also Visser-Wijnveen et al. 2012). Nevertheless, the empirical results about the identified, introjected and extrinsic motivation of professors to act as reviewers show an expected pattern of interrelations, which indicates their validity (see methodology section). Second, the MWMS items about amotivation were asked in a separate question at the end of the questionnaire to avoid context effects found during pretesting (see also Mummendey and Grau 2014; Schwarz and Sudman 1992). Also due to context effects found during pretesting, third, the MWMS items were contextualized. The result of the contextualization is that the motivation questions were neither boycotted nor produced a considerable number of missing responses to the motivation items.

The contextualized version of the MWMS proved useful for examining the motivation of reviewers involved in accreditation and evaluation procedures. In hindsight, it is not surprising that intrinsic motivation did not emerge as a standalone form of motivation because reviewing is seldom an activity that brings fun and enjoyment by itself. This study is one of the first to examine discrete behavior as an outcome of different forms of motivation, and shows that the second most autonomous form of motivation according to SDT can be linked to a likely engagement in the reviewer role in the future, thus supporting the SDT assumption about autonomous, i.e., intrinsic and identified motivation.

Acknowledgments For their feedback on different draft versions of the manuscript, the authors would like to extend sincere thanks to Miriam Kraus, Georg Krücken, Christian J. Schmid and the unknown reviewer.

Funding Open Access funding enabled and organized by Projekt DEAL.. Open Access funding enabled and organized by Projekt DEAL. This research was funded by the German Ministry for Education and Research (Bundesministerium für Bildung und Forschung; Grant Number 01PY13017). 


\section{Compliance with ethical standards}

Conflict of interest The authors declare that they have no conflict of interest.

Open Access This article is licensed under a Creative Commons Attribution 4.0 International License, which permits use, sharing, adaptation, distribution and reproduction in any medium or format, as long as you give appropriate credit to the original author(s) and the source, provide a link to the Creative Commons licence, and indicate if changes were made. The images or other third party material in this article are included in the article's Creative Commons licence, unless indicated otherwise in a credit line to the material. If material is not included in the article's Creative Commons licence and your intended use is not permitted by statutory regulation or exceeds the permitted use, you will need to obtain permission directly from the copyright holder. To view a copy of this licence, visit http://creativecommons.org/licen ses/by/4.0/.

\section{References}

Akkreditierungsrat. 2001. Arbeitsbericht 1999/2000. Bonn.

Akkreditierungsrat. 2013. Regeln für die Akkreditierung von Studiengängen und für die Systemakkreditierung (Drs. AR 20/2013). Bonn.

Arribas-Ayllon, Michael, and Andrew Bartlett. 2014. Sociological Ambivalence and the Order of Scientific Knowledge. Sociology 48(2): 335-351.

Armstrong, J. Scott. 1997. Peer Review for Journals: Evidence on Quality Control, Fairness, and Innovation. Science and Engineering Ethics 3: 63-84.

Baumann, Janosch, and Georg Krücken. 2019. Debated Legitimacy: Accreditation in German Higher Education. Higher Education Policy 32(1): 29-48.

Bornmann, Lutz. 2011. Scientific peer review. Annual Review of Information Science and Technology 45: $197-245$.

Bornmann, Lutz, Sandra Mittag, and Hans-Dieter Daniel. 2006. Quality assurance in higher education - Meta-evaluation of multi-stage evaluation procedures in Germany. Higher Education 52(4): 687-709.

Bronfenbrenner, Ueli. 1979. The Ecology of Human Development. Cambridge: Harvard University Press.

Bundesverfassungsgericht. 2016. Wesentliche Entscheidungen zur Akkreditierung von Studiengängen muss der Gesetzgeber selbst treffen (1 BvL 8/10). Beschluss vom 17.02.2016.

Cole, Stephen. 1998. How Does Peer Review Work and Can It be Improved? Minerva 36(2): 179-189.

Clark, Burton R. 1983. The Higher Education System. Academic Organization in Cross-National Perspective. Berkeley: University of California Press.

Curtin, Patricia A., John Russial, and Alec Tefertiller. 2018. Reviewers' Perceptions of the Peer Review Process in Journalism and Mass Communication. Journalism \& Mass Communication Quarterly 95(1): 278-299.

Deci, Edward L., and Richard M. Ryan. 1994. Intrinsic motivation and self-determination in human behavior, 5th ed. New York: Plenum.

Derrick, Gemma E., and Gabrielle N. Samuel. 2016. The Evaluation Scale: Exploring Decisions about Societal Impact in Peer Review Panels. Minerva 54(1): 75-97.

De Solla Price, Derek, and Donald Beaver. 1966. Collaboration in an invisible college. American Psychologist 21(11): 1011-1018.

ENQA (2015). Standards and Guidelines for Quality Assurance in the European Higher Education Area $(E S G)$. Brussels.

Esdar, Wiebke, Julia Gorges, and Elke Wild. 2016. The role of basic need satisfaction for junior academics' goal conflicts and teaching motivation. Higher Education 72: 175-190.

Foss, Nicolai J., Dana B. Minbaeva, Torben Pedersen, and Mia Reinholt. 2009. Encouraging knowledge sharing among employees: How job design matters. Human Resource Management 48(6): 871-893.

Fox, Charles W., Arianne Y.K. Albert, and Timothy H. Vines. 2017. Recruitment of reviewers is becoming harder at some journals: A test of the influence of reviewer fatigue at six journals in ecology and evolution. Research Integrity and Peer Review 2(3). https://doi.org/10.1186/s41073-017-0027-x.

Frey, Bruno S. 2003. Publishing as prostitution? Choosing between one's own ideas and academic success. Public Choice 116(1): 205-223. 
Gagné, Marylène, et al. 2015. The Multidimensional Work Motivation Scale: Validation evidence in seven languages and nine countries. European Journal of Work and Organizational Psychology 24(2): 178-196.

Gallo, Stephen A., Lisa A. Thompson, Karen B. Schmaling, and Scott R. Glisson. 2020. The Participation and Motivations of Grant Peer Reviewers: A Comprehensive Survey. Science and Engineering Ethics 26: 761-782.

GFSO - Statistisches Bundesamt. 2016. Personal an Hochschulen 2015. Fachserie 11, Reihe 4.4. Wiesbaden.

Hackett, Edward J. 1990. Science as a vocation in the 1990s: The changing organizational culture of academic science. Journal of Higher Education 61(3): 241-279.

Henkel, Mary. 2005. Academic identity and autonomy in a changing policy environment. Higher Education 49(1-2): 155-176.

Hillcoat-Nallétamby, Sarah, and Judith E. Phillips. 2011. Sociological Ambivalence Revisited. Sociology 45(2): 202-217.

Hirschauer, Stefan. 2004. Peer Review Verfahren auf dem Prüfstand. Zum Soziologiedefizit der Wissenschaftsevaluation. Zeitschrift für Soziologie 33(1): 62-83.

Hochschulrektorenkonferenz. 2016. Neuordnung des Akkreditierungssystems. Bonn.

Howard, Joshua L., Marlène Gagné, and Julian S. Bureau. 2017. Testing a continuum structure of selfdetermined motivation: A meta-analysis. Psychological Bulletin 143(12): 1346-1377.

Klenke, Dietmar. 2012. Die Einführung der W-Besoldung: Ihre Entstehung aus zeitgeschichtlicher Perspektive. Forschung \& Lehre 19(3): 190-193.

Kultusministerkonferenz. 2017a. Studienakkreditierungsstaatsvertrag, Bonn.

Kultusministerkonferenz. 2017b. Musterrechtsverordnung Akkreditierung vom 07.12.2017. Bonn.

Kogan, Maurice, and Ulrich Teichler. 2007. Key Challenges to the Academic Profession and its Interface with Management: Some Introductory Thoughts. In Key Challenges to the Academic Profession, eds. Maurice Kogan and Ulrich Teichler, 9-16. Kassel: INCHER-Kassel.

Koestner, Richard, Gaetan F. Losier, Robert J. Vallerand, and Donald Carducci. 1996. Identified and introjected forms of political internalization: Extending self-determination theory. Journal of Personality and Social Psychology 70(5): 1025-1036.

Lamont, Michèle. 2009. How Professors Think. Cambridge: Harvard University Press.

Lamont, Michèle. 2012. Toward a Comparative Sociology of Valuation and Evaluation. Annual Review of Sociology 38: 201-221.

Langfeldt, Liv. 2001. The Decision-Making Constraints and Processes of Grant Peer Review, and Their Effects on the Review Outcome. Social Studies of Science 31(6): 820-841.

Langfeldt, Liv. 2006. The policy challenges of peer review: Managing bias, conflict of interests and multidisciplinary assessments. Research Evaluation 15(1): 31-41.

Langfeldt, Liv, Björn Stensaker, Lee Harvey, Jeroen Huisman, and Don Westerheijden. 2010. The role of peer review in Norwegian quality assurance. Potential consequences for excellence and diversity. Higher Education 59: 391-405.

Leahey, Erin. 2007. Not by Productivity Alone: How Visibility and Specialization Contribute to Academic Earnings. American Sociological Review 72(4): 533-561.

Macfarlane, Bruce. 2010. Professors as Intellectual Leaders: Formation, Identity and Role. Studies in Higher Education 36(1): 47-73.

Martin, Ben R., Martin Bell, Michel Callon, Hariolf Grupp, Fumio Kodama, Stefan Kuhlmann, Lee Fleming, Nick von Tunzelmann, and Walter Powell. 2009. EES and the continuing evolution of research policy. Research Policy 38(5): 695-699.

Merton, Robert K. (1973) [1942]. The Normative Structure of Science. In: The sociology of science. Theoretical and empirical investigations ( $2^{\text {nd }}$ Impr.), ed. Robert K. Merton, Chicago: Univ. of Chicago Press.

Merton, Robert K. 1976. Sociological Ambivalence and other Essays. New York: Free Press.

Mittag, Sandra. 2006. Qualitätssicherung an Hochschulen. Eine Untersuchung zu den Folgen der Evaluation von Lehre und Studium. Münster: Internationale Hochschulschriften.

Mulkay, Michael. 1976. The mediating role of the scientific elite. Social Studies of Science 6: 445-470.

Müller, Lars, and Christian Schneijderberg. 2020. The Emergence of the Organizational Academic Profession: Vertical differentiation of German universities and the research-teaching nexus. Higher Education Forum 17. http://doi.org/10.15027/48954.

Mummendey, Hans Dieter, and Ina Grau. 2014. Die Fragebogen-Methode. Grundlagen und Anwendung in Persönlichkeits-, Einstellungs- und Selbstkonzeptforschung, 6th ed. Göttingen: Hogrefe. 
Musselin, Christine. 2013a. How Peer Review Empowers the Academic Profession and University Managers. Changes in Relationships between the State, Universities and the Professoriate. Research Policy 42: 1165-1173.

Musselin, Christine. 2013b. Redefinition of the relationships between academics and their university. Higher Education 65: 25-37.

Nobarany, Syavash, Kellogg S. Booth, and Gary Hsieh. 2015. What Motivates People to Review Articles? Journal of the Association for Information Science and Technology 67(6): 1358-1371.

Northcraft, Gregory B., and Ann E. Tenbrunsel. 2011. Effective matrices, decision frames, and cooperation in volunteer dilemmas: a theoretical perspective on academic peer review. Organization Science 22(5): 1277-1285.

Olbrecht, Mareike, and Lutz Bornmann. 2010. Panel peer review of grant applications. What do we know from research in social psychology on judgment and decision-making in groups? Research Evaluation 19: 293-304.

Power, Michael. 1999. The Audit Society. Rituals of Verification. Oxford: Oxford University Press.

Pusser, Brian. 2008. The state, the market and the institutional estate: Revisiting contemporary authority relations in higher education. In Higher Education: Handbook of Theory and Research (Vol. 23), ed. John C. Smart, 105-139. New York: Agathon.

Ringer, Fritz K. 1990 [1969]. The Decline of the German Mandarins: The German Academic Community, 1890-1933. Wesleyan University Press.

Roumbanis, Lambros. 2019. Peer Review or Lottery? A Critical Analysis of Two Different Forms of Decision-making Mechanisms for Allocation of Research Grants. Science, Technology, \& Human Values 44(6): 994-1019.

Sanford, Nevitt. 1966. Self \& Society: Social Change and Individual Development. Atherton Press.

Schimank, Ulrich. 2005. 'New Public Management' and the Academic Profession: Reflections on the German Situation. Minerva 43(4): 361-376.

Schmid, Christian J., and Sabine Lauer. 2016. Institutional (teaching) entrepreneurs wanted! - Considerations on the professoriate's agentic potency to enhance academic teaching in Germany. In Organizing academic work in higher education, eds. Liudvika Leisyte and Uwe Wilkesmann, 109-131. New York: Routledge.

Schneijderberg, Christian, and Isabel Steinhardt. 2019. Accreditation of X Qualities Instead of Quality X: A Normative Analysis of Criteria of the German Higher Education Accreditation Regime. Higher Education Policy 32(1): 5-28.

Schneijderberg, Christian, and Ulrich Teichler. 2018. Doctoral Education, Training and Work in Germany. In Doctoral Training for Knowledge Society, eds. Jeol C. Shin, Barbara M. Kehm, and Glen Jones, 13-34. Dordrecht: Springer.

Scholkmann, Antonia. 2011. Deans in German Universities: Goal acceptance and task characteristics. Tertiary Education and Management 17(4): 337-353.

Schroter, Sara, Trish Groves, and Liselotte Højgaard. 2010. Surveys of current status in biomedical science grant review: funding organisations' and grant reviewers' perspectives. BMC Medicine 8(1): 62 .

Schwarz, Norbert, and Seymour Sudman (eds.). 1992. Context effects in social and psychological research. New York: Springer.

Serrano-Velarde, Kathia. 2014. Rising Above Institutional Constraints? The Quest of German Accreditation Agencies for Autonomy and Professional Legitimacy. Minerva 52(1): 97-118.

Solesbury, William. 1996. Scientific research: demystifying peer review. Research Evaluation 6(1): 19-23.

Stichweh, Rudolf. 1994. Wissenschaft, Universität, Profession. Frankfurt a.M.: Suhrkamp.

Trowler, Paul. 2014. Depicting and researching disciplines: Strong and moderate essentialist approaches. Studies in Higher Education 39(10): 1720-1731.

Visser-Wijnveen, Gerda J., Ann Stes, and Peter van Petegem. 2012. Development and validation of a questionnaire measuring teachers' motivations for teaching in higher education. Higher Education 64(3): 421-436.

Ware, Mark. 2011. Peer review: Recent experience and future directions. New Review of Information Networking 16: 23-53.

Zaharie, Monica Aniela, and Codruta Luminita Osoian. 2016. Peer review motivation frames: A qualitative approach. European Management Journal 34(1): 69-79.

Publisher's Note Springer Nature remains neutral with regard to jurisdictional claims in published maps and institutional affiliations. 